\title{
Care, collaboration and critique: The intersection of creativity and wellbeing in older women
}

\author{
Lila Moosad · Cathy Vaughan
}

\begin{abstract}
In this paper, we investigate the intersection of creativity and wellbeing for older women based on the experience of a group who participated in a photography project in Melbourne, Australia. We draw on interviews with 18 women who participated in the 500 Strong photography project in 2019. This project aimed to raise the visibility and dispel stereotypical portrayals of older women through an exhibition of nude photographs of more than 400 women aged over 50 from Melbourne and regional Victoria. We suggest that, for the participants in this study, creativity and wellbeing are interlinked through the domains of care, collaboration and critique. For some women, the photography experience was an act of care, to liberate themselves from negative images of ageing and celebrate their bodies. For others, participation was a creative venture through which they could collectively acknowledge the contributions of older women. Some women participated in the photography project to raise awareness of, and critique policies detrimental to, older women's wellbeing. The findings of this qualitative research with older women support the arguments that: 1) wellbeing is understood by the participants within a matrix of personal and structural security; 2) creativity is a critical and under-theorised dimension through which women make these understandings visible. This study contributes to literature on contemporary ageing that contests singular notions of decline and loss and to theorizing the use of creativity in wellbeing frameworks.
\end{abstract}

Keywords: ageing, creativity, photography, wellbeing, women

\section{Introduction}

Norn, who is 86, has invited me (first author) to interview her at her house. Her granddaughter who lives with her lets me in. Over a cup of tea, Norn reflects on how she came to be involved in a photography project called 500 Strong. She has a personal connection with the photographer, and found posing for her a reassuring and comfortable experience. When asked what prompted her to participate in the project, she remarked she was initially daunted but she has always involved herself in creative community ventures and this project offered possibilities for richer conversations beyond seeing ageing as an economic burden. "New ways of seeing women are creative acts in themselves", she concludes. (Field notes, September 2019)

Arts-based activities and creative engagement have been shown to have positive effects on the personal health and wellbeing of older adults and to contribute to improvements in some physiological outcomes (Patterson and Perlstein, 2011; Liddle et al., 2013; Baker, 2014; Davidson et al., 2014; Cann, 2016; Poulos et al, 2018; Boyce-Tillman, 2019). Cohen (2006) outlines the positive health outcomes that older people experience through their participation in creative 
activities. These activities not only arrest cognitive decline, they also contribute to an overall improved quality of life and feelings of positivity. In Australia and elsewhere, many arts initiatives involving older adults have been used in structured ways in residential and community aged-care settings, often with older people who are experiencing physical and cognitive impairment (Joseph and Southcott, 2013; Archibald and Kitson, 2019; Bellass et al, 2019; Miller et al, 2019).

This article delves into the links between creativity, wellbeing and older women through an exploration of women's often creative participation as co-creators in a photography project. Photographers like Donnigan Cumming, Anne Noggle and Melanie Manchot have photographed naked bodies of older women to disrupt stereotypical representations of age and gender, while other photographers like Cindy Sherman and Rosy Martin have used their own bodies with props to critique ageing norms for older women (Hodgson, 2018). The 500 Strong photography project is unique in its aim to create alternative images by bringing together up to 500 individual, naked images of older women. The participants came up with their own concept of how they wanted to be represented through their choice of props and poses. Rather than view creativity as "the mysticism of special talents and abilities" (Nielsen, 2018, p. 1), we use the notion of "everyday creativity" (Amabile, 2017). Amabile is interested in "the rich variety of emotions, perceptions, and motivations" (p. 336) that individuals engaged in creativity are able to describe. We take this notion of creativity to be a generative one and one that is intrinsically linked to participants' life experiences and their understandings of wellbeing and ageing. In this article, we explore the reasons why the women were attracted to contributing to alternative images of ageing, how they chose to represent themselves during the photography session, and how this was linked to their understandings of wellbeing.

If anything the proliferation of wellbeing research has shown that definitions of wellbeing and evaluation methods have never been truly stable or settled (Dodge et al., 2012). Studies have progressed from their foundations in "happiness and positive affect" (Adler \& Seligman, 2016, p. 5) to broader understandings that acknowledge its eudaimonic qualities. In these latter studies, wellbeing is observed in and across various domains of life - relationships, employment, physical and emotional health, personal growth and personal care - however, definitional ambiguities persist (Seligman, 2011; Ryff, 1995). Dodge et al. (2012) propose a definition that recognises the multi-faceted qualities of wellbeing. They suggest wellbeing is "the balance point between an individual's resource pool and the challenges faced" (p. 230), where resources and challenges can be psychological, social and physical. From this perspective, wellbeing fluctuates depending on the balance between a person's resources and the challenges they face at any particular point in their lives. In recent times, anthropologists have contributed to wellbeing scholarship through an ethnographic approach that foregrounds people's experiences and a theoretical assumption that wellbeing is generated within communities through social processes (Calestani, 2013; Fischer, 2014). More recently, White (2017) has expanded the concept of relational wellbeing through her work with communities in rural India and Zambia. In this article, we foreground these relational and social understandings of wellbeing in favour of its economic and psychological conceptualisations.

The ever-expanding discourse around ageing has generally been confined to certain key themes. The medical approach is primarily focused on the concept of a process of physical and mental decline. The policy-oriented material places a heavy emphasis on questions of the fiscal pressures of supporting an ageing population. Much of this discussion has framed ageing as "a deficit" or a problem that "must be managed" by "individuals" (Asquith, 2009, p. 256). However, a fruitful approach in recent research recognises ageing in a more complex and nuanced context 
(Holstein and Minkler, 2007; Dillaway and Byrnes, 2009; Martin and Twigg, 2018; Pilcher and Martin, 2020). This literature has placed more emphasis on power relationships, environmental health determinants and "the biopolitics of health inequalities" (Katz and Calastanti, 2015, p. 29). Several contributors have incorporated visual research to engage more broadly with ageing discourses, away from strictly biomedical constructions and discourses "steeped in a language of loss, erosion, lack, decline" (Tulle and Krekula, 2013, p. 9).

While this article focuses on a specific artform - photography - to explore connections between creativity, ageing and wellbeing, many of the women interviewed for the study were already engaged in a range of other creative practices such as singing, drawing, theatre, performance, and writing. Their interviews reflected their broader views on the importance of creative practices to their wellbeing and ageing experiences. While their participation in the 500 Strong photography project was a one-off occasion, it prompted reflections on reasons for participating in the context of their creative practices generally. Many of the participants, for example, put thought into the props they would use for their photography session and wanted the session to align with their life biographies and interests.

While sipping tea, Norn noted that "The truth of our bodies is not readily available, much of women's true selves in hidden by fashion and convention". For the participants in this study, being a part of 500 Strong gave them the opportunity - or, as some of the women might say, the responsibility - to uncover their true selves with all the complexities, ambiguities and contradictions of their lives. For some of the women, the creative act was in the photography session itself. For others it was more significantly committing to the objectives of the 500 Strong project; that is, to provide a different set of narratives, to shift conversations around portrayals of older women and their visibility. Participating in their photography session was, as many participants suggested, an act of disruption against constructed norms of passivity and invisibility in dominant narratives about older women. Through their participation, the women continue the tradition of subverting gendered norms through creative arts (Richards et al 2012).

While the photographer (Ponch Hawkes) made the final decision in the selection and arrangement of the images, the women, through the act of participation, provided the context to the debates that the photography exhibition is expected to generate. In this article we argue that the dimensions of care, collaboration and critique that underpin the reasons for participating "creatively" are useful signposts to alternative ageing and wellbeing discourses.

\section{Methodology}

The 500 Strong photography project was part of a wider initiative, Flesh After Fifty, developed in response to the lack of positive visual representations of older women in art and media. Flesh After Fifty would be a series of art installations and community engagement events to discuss issues of older women's health and wellbeing and to contest the negative portrayals of women's ageing. For 500 Strong, 500 women aged over 50 were recruited from across the state of Victoria and asked to pose for nude photographs of themselves using props and poses of their choice. The women had the option of partly covering their bodies and obscuring their faces with their props. Ponch Hawkes, a well-known Australian photographer, took their photographs and these were scheduled to be exhibited in March 2020. This exhibition has since been postponed until February 2021 due to restrictions imposed as a result of the COVID-19 pandemic. Many of the women will not have seen their images prior to the exhibition. We invited 18 women who had contributed to the 500 Strong project to participate in an interview. The women were recruited to represent age and geographical cohorts. The interviews were conducted by the first author between August 2019 and February 2020. 
The interviews explored women's motivation for participating in the photography project by asking them to reflect on their experience of the session. The interviews also discussed women's experiences of getting older and their reflections on wellbeing. The questions aimed to draw out women's embodied experiences of the photography session as well as the complex factors that contributed to their experiences of ageing.

The youngest participant in the study was 50 years old and the oldest was 86 . Two of the participants were visually impaired. All participants were given written information about the project and they provided written consent prior to participation in the interviews. For the two participants who were visually impaired, project information and the details of the consent form were verbally summarised before the start of their interviews. The interviews were audiorecorded with the consent of the participants. The interviews were transcribed and thematically analysed by the first author for recurring, similar and divergent ideas and to identify the threads across creativity, ageing and wellbeing (Bryman, 2012). The initial codes were derived from the data and later grouped into the themes of care, collaboration and critique. These themes were finalised through a close reading of the transcripts and quotes that identified the women's relationships with their own bodies, with other older women and with concerns that impact on their wellbeing and their experiences of ageing.

In this article the women are identified by a pseudonym except where they chose to use their own name, in which case they are identified by the first letter of their name. The University of Melbourne's Health Sciences Human Ethics Sub-Committee granted approval for this study in August 2019.

\section{Results}

Ageing, wellbeing and creativity

The themes emerging from the interviews with participants in this study alerted us to the multidimensional links across ageing, wellbeing and creativity. Their participation in the creative project offered them ways to reflect on their current lives and experiences, not in static and bounded ways, but in ways that stretch across temporal lines. Sabeti (2015) refers to creativity in terms of improvisation, "simply our way of living and being in the world", rather than innovation or the "production of something 'new" ( p. 217). It is this ongoing social and cultural recalibration of individual and relational lives, Sabeti would argue, that generates wellbeing.

This study draws from the works of medical anthropologist Sarah Lamb (2014; 2018), whose ethnographic research contests the cultural assumptions underlying the dominant ageing discourses that "overemphasise independence, prolonging life and declining to decline" (Lamb, 2014, p. 42). These discourses, according to Lamb, are embedded in cultural and biomedical assumptions that tend to obscure the realities of decline that accompany the processes of ageing. The flaw of this paradigm, according to Lamb, is a failure to acknowledge that decline is indeed a natural part of ageing and "need not be incompatible" with enjoying life at a late stage of one's life (Lamb 2014, p. 51). Lamb's (2018) study illustrates how cultural, societal, medical, political and personal experience are all constituents giving "meaning to the body, self and aging" (p. 265). It is in this "confluence of factors" that ageing is constructed and experienced (p. 265).

Echoing Lamb's critique, several feminist/critical gerontologists argue that policy discourses frequently fail to analyse the implications of social and economic forces, the impacts of which are highly variable depending on women's circumstances (Holstein and Minkler, 2007; Dillaway and Byrnes, 2009; Freixas et al., 2012). Critical gerontology addresses gendered structures of employment as well as unpaid labour as key factors shaping the disadvantages experienced by many older women. The impacts on women's ageing processes need much greater attention from 
researchers. Qualitative research into creative projects has an important role in drawing attention to the structural factors that marginalize older women. Also missing from the "decline and deficit" model of ageing (Webster-Wright, 2019, p. 98) is the vocabulary to express the ways in which women acknowledge their physical ageing at the same time as they embrace that process through creative expression.

The work of sociologists Twigg and Martin (2015) linking the fields of ageing to visual arts research points to an insightful, new direction for analysis. Like Lamb, their multidisciplinary approach contests the mainstream "universalising" tendency of ageing discourses while providing scope for incorporating broader theoretical perspectives. Twigg and Martin's (2015) analysis draws on the life experiences of age and acknowledges the breadth and diversity of women's experiences. Their use of visual research methods to elicit the richness of lives as a way to counter the "visual culture that systematically devalues and erases age" (Twigg, 2013, p. 101) has also linked "micro processes of daily life ... to wider sociocultural discourses" (Twigg and Martin, 2015, p. 356). For many of the women, drawing attention to material and structural barriers faced by women was a key reason for their participation in the project.

Many of the women saw themselves as being creative and were motivated to participate in the photographic project as an appealing creative outlet. For others, the experience of participating was a response to their life experiences and concerns about their own ageing process. Terms like "dignified" and "private" and phrases such as "atmosphere of trust" were used by the women to describe their experience of being photographed naked. The photographer had created a studio environment where the lighting was dim and where women felt safe to portray themselves in whatever way they wanted. Some of the women already had a connection with the photographer through other artistic collaborations and trusted her and her representation of their bodies. Others had heard about the project through social media or through their friends.

The ways in which women spoke about their reasons for participating in the project were wide-ranging. For Wanda Lust, aged 61, it was a "personal crusade to become more visible as I age". She linked her personal campaign to be visible to the collective aim of taking action against the prevailing discourses to which older women were subjected. Participant A (aged 70) wanted to illustrate that "life can still be joyous as one is ageing, that you can leave stuff behind that's been a bit baggage-like and get on with doing more of what you want". Participant E (aged 53), who was also vision impaired, decided to get involved because she had "had enough of everybody telling me what I should do and shouldn't do". Participant D's (aged 66) motivation to participate arose from a desire to support a friend who had had a mastectomy and had participated in the photography event. Participant D also wanted to contribute to broader discussions about women's ageing experiences. Creativity and wellbeing were not discussed by the women as solitary categories; these were conceptualized through the women's life experiences and their cultural, social and political worldviews.

Ana (aged 68) had been diagnosed with scoliosis a few years prior and her spine deteriorated while she was also dealing with critical family illnesses and death. She had been a weaver of textiles all her life but was now unable to work with large weaving pieces. "I' $m$ at a stage where I've sort of dealt with the fact that I've got a terrible back and I know how to manage it", she said, when asked what prompted her to participate in the photography project. "I am at the best stage of my life in terms of independence and confidence", she continued. Ana's "decline" does not prevent her from continuing her artistic practice in a modified way and through mentoring other weavers. By viewing ageing and wellbeing as located in their social lives and relationships, 
the participants in this study offer a lens for exploring the interrelationships across creativity, ageing and wellbeing.

For many participants the photography event afforded creative opportunities in being able to choose poses and props. The participants were focused on the representation of their bodies but they were also willing to explore the "complex and diverse interconnections" between their bodies and the contexts of their lives (Martin and Twigg, 2018, p.3). The themes arising from our analysis of the interview transcripts suggest that notions of creativity, wellbeing and ageing are linked through the domains of care, collaboration and critique. These domains are often amorphous, overlapping and sometimes contradictory, but they offer insights into the dynamic processes of creativity, wellbeing and ageing.

\section{Creativity as Care}

As a creative undertaking, the 500 Strong project departed from discourses "that have normalized the un-photographability of ageing female bodies" (Tiiddenberg, 2018, p. 63). Science and Technology Studies scholar, Puig de la Bellacasa, asserts that care is "an affective state, a material vital doing and an ethico-political obligation" (Puig de Bellacasa quoted in Martin et al 2015, p. 626). For de la Bellacasa, care is an active practice and has a political component. We suggest that by participating in the photography session, the participants were actively making older women's bodies photographable. For them, joining in the photoshoot was an act of care for themselves and for older women more generally. Some women had not previously perceived their participation in that way but the experience encouraged them to comment on changes to their physical appearance and the state of their bodies as a result of illness, childbirth and the process of ageing. This version of care included challenging dominant narratives about older women's bodies while celebrating their lives and bodies. The participants spoke poignantly about their motivation for participating, as a way to acknowledge their personal hurdles and milestones while engaging playfully in front of the camera. For some of the women, participating in the photography session was a way of showing their healthy and functional bodies which they had looked after by staying active. The notion of care expressed through their creative act, some of the women suggested, would help foster alternative and positive representations of older women.

The women had agency over how they wished to pose and participants contrasted this with their experiences of how older women were forced into a particular look by mainstream media and advertising, whether it be images of older women with white hair and glasses or welldressed older women going on cruises. The women in this study were able to pose with their choice of props, which variously included fans, books and scarves, noting that in some cases these symbolised their stories of migration, grief and survival.

Health, or the celebration of health, was a motive behind participating in the project. Ana engaged in the project as an acceptance of her health but also as recognition that she was able to continue her creative pursuits without being defined by her back condition. "My back's actually worse than it was but I'm fine", she said. Ana had held up a piece of her weaving as her prop and it served as a symbol of the physical labour required to produce her work of art. She wondered whether her photograph would detect the curvature of her spine.

For Wanda Lust, participating in the photography event was personal and political. It was a way of caring for herself and for older women generally who are expected to fade into the background as they get older. 
While Wanda masked her face with a black veil, she wanted her tattoos and scar to be in the photograph. She had grown up with anxieties about her body but for the photography session she was keen to foreground her tattoos and her scar so she was "able to stand up and show the stories that are on my body". She stated:

I have very personal reasons for doing it. There was a whole kind of constellation of things - it all kind of happened at the same time. I've had quite a lot of surgery over the last 20 years including a full hysterectomy so I've got a big scar on my belly. I also have tattoos which I was always too terrified to ever disclose to my father.

For many of the women, participating in the photography session was an invitation to take part in something whimsical. The playfulness generated by the photography experience also appealed to the women's sense of care and play. For Peggy (aged 64), it was a place to "cavort in a very gentle way". She had recovered from breast cancer and was regaining her energy levels after the radiotherapy treatment. She did not see herself as an active person but was able to enjoy this experience. The capturing of movement in her imagery was a contrast to the passive images often seen of female bodies in art. It offered an insight into "the joyousness of life, not a downward decline".

The invitation to pose and move during the photography event was also seen by the women as an invitation to be playful. They were aware that their bodies had changed over the years, as a result of surgery, of having children and other events in their lives. Many women had over time shifted their relationship to their bodies and no longer felt they needed to match the ideal that had been demanded of them throughout their lives. When Abby (aged 60) went to her photography session, she wanted to present her best angle. She stated:

Cos I went in there wanting to show the best bits, and I came out thinking, well every bit is good and I didn't have to sort of pick and choose, just sort of this is all of me and I didn't have to think about I have to show this bit or that bit or so in that sense it maybe made me a bit more accepting of my whole body.

She wanted her photograph to be taken in a particular way and there was a tension between what she thought would make for a good photograph and what the photographer would see as an interesting image. For Abby, participating in the photography session allowed her to "accept my lumps and bumps" and "not to be afraid to show it to people".

For Lisa (aged 53) and Participant E (aged 50), the pressures of ageing and the visibility/invisibility tension that many of the other participants mentioned did not have the same resonance. They were both born visually impaired and their reasons for participating were prompted by narratives they had been subjected to all their lives. As Lisa stated:

All my life I've been called ugly or disabled or something like that from various people but I don't see myself as that. I just wanted to say that I am who I am. I'm proud of who I am.

As far as Lisa was concerned, she was an average person and she wanted to present that image to the world. While Participant E simply wanted to engage in the project because she had never done anything like it before, for both Lisa and Participant B, participating in the photography session was an opportunity to explore an interesting idea for themselves and be supported by their friends in their decision. 
Yiola (aged 55) wanted an enduring kind of visibility and thought the photograph would be a legacy of her life, stating, "there will be a portrait of me somewhere naked when I am gone". She also wanted to make visible her commitment to social justice by using a book on cultural diversity as her prop. She linked her participation in the project to the bigger story of her parents' migration to Australia and their contribution to Australian society.

\section{Creativity as Collaboration}

The project is not a project about me or any individual person and so the photograph is one that would best fit the need of a whole project, which would best represent a little bit of the idea of the diversity of women. So I was not concerned. Once I decided I didn't think of it being myself except in that moment[ary] decision about cloaking my face. Because my body is another body in that particular context. I have donated the image of my body to a larger cause than what I've been thinking about myself. (Participant Norn)

For many of the women, the photography project was not an event about individuals, it was viewed by them as a collaborative endeavor, as a way of initiating broader conversations about depictions of older women in the media and the arts and their invisibility. Women like Norn (aged 86) and Wordsworth (aged 73) drew on the history of collectivism and women's accomplishments that propelled them to participate in the photography session. They recalled key events in Australia that progressed the lives of women such as access to tertiary education and being able to remain in the workforce after getting married. For example, Wordsworth recalled, "I come from a working-class background, but education saved me". Their individual experiences of being refused a mortgage because they were young women or their experiences in the "gendered boardroom" inspired them to participate in the project and challenge dominant narratives, such as those that frame ageing in terms of decline and invisibility.

There was also a sense of collaboration with the photographer as they negotiated the props and the accompanying poses and these interactions were playful and whimsical. At other times there were conversations with other women who had also arrived for the photography shoot. Many of the women spoke of a sense of being part of a photographic collective that would shift conversations about older women's bodies. They contested the images of perfection they saw on television and in magazines and wanted their "unphotoshopped" images to be on display. Many of the women in this study were also actively collaborating in their neigbourhoods on projects ranging from climate change, community choirs, theatre groups and volunteering in hospitals. Their participation in the photo shoot was an extension of this collaborative activism generally reflected in their lives.

Lovely L (aged 66) summarized her own participation in the photography shoot as a "dignified and private" event which led to her deciding to take on a bigger role with the wider Flesh after Fifty project to raise awareness of the ageism that exists against older women and their underrepresentation in public platforms. Allocated an ambassadorial role, she assisted with recruiting older women for the 500 Strong project and provided support during the photography sessions.

As practicing artists, many of the women were interested in supporting other artists and saw their participation as contributing to a larger cause. Rose (aged 75), who is a photographer herself, recalled the artist Louise Bourgeois who was producing her best works in her later years. Creativity was a big part of Rose's life: at 75, she was preparing for an overseas photography 
exhibition. Prevailing attitudes about older women, she thought, underestimated their creative potential. Rose's sentiments were shared by Participant A (aged 70), who stated:

It occurred to me just as we were talking all the little play mobiles, little figurines, the granny always is white-haired with a bun. So even those sorts of things, there's mummy and daddy and there's this old person who's a bit decrepit with a stick. And public signs always have people bent over with a stick.

These simplified depictions did not offer young and older people a range of examples of ageing to draw from; but rather, reinforced the narratives of decline and dependence associated with ageing. For Participant A, such singular depictions of ageing created a disconnect with younger people by characterizing older people as "other". Actively participating in activities that counter this narrative, Participant A belongs to a multigenerational choir that has provided her with a weekly dose of energy. She is also part of a repair café where people, young and old, bring things to repair or mend and socialise. This sense of working collaboratively with other older women and across generations was a motivation for many of the women to take part in the photography session.

\section{Creativity as Critique}

I wore a mask, it was something I bought at the two-dollar shop. So just a blank mask, then I put a lacy thing across the eyes so, was I being creative? Probably. I thought it was a good image. Did I find it empowering? No. Did I find it disempowering? No. I don't think that was a concept that came into it for me. (Participant D)

Participant D (aged 66) is still working professionally so she decided to wear a mask to obscure her face. Her reasons for participating in the project were to be part of a collective set of images, rather than any sense of personal liberation. As a health lawyer, she had reflected on older women's experiences in the health system where women were sometimes viewed as "a bunch of body parts". For her, the photography project was about shifting discussions beyond decay and decline to incorporate broader issues of creative options for older women. It was about questioning "her place in the world" and the ways in which she could contribute to social change. Participant D's commitment to raising awareness of issues of family violence and the increasing levels of homelessness among older women could be assisted through her participation in creative projects like 500 Strong.

Participant D's concerns are supported by evidence that shows a 31\% increase in the number of older women in Australia experiencing homelessness between 2011 and 2016 (Australian Association of Gerontology, 2018). She was critical of ageing discourses that prioritised and promoted the needs of the individual, suggesting that "collective wisdom" and having "a sense of community" was going to effect change, not individual-level analyses. Healthy ageing for D was about finding solutions to problems that impact on society whether they are creative models of housing or living arrangements. She drew from her experiences in the legal profession to highlight gender inequities saying, "in the legal profession, it's the invisibility of the experiences of the older women, whereas the older men, they are absolutely acknowledged for their wisdom and the women are not". She used her first hand experience of the structural ageism in the law to draw attention to issues faced by older women and to critique the double standards that exist 
in society. Participating in the project was a way for $\mathrm{D}$ to be contributing to broader conversations of change.

The potential of the 500 Strong project to make a collective critique of current ageing policies and their impact on older women was also echoed by Wanda. Similar to D, she did not see her participation in the project as a cathartic act or one of empowerment, stating, "I left with the same issues and shame and doubt that I went in with". Wanda's interest lay in using art as a form of activism to disrupt reductive discourses of ageing. Rather than viewing age as a personal responsibility, she was keen to use the collective portraits to raise awareness of structural disadvantage experienced by older women and to move beyond stereotypical representations of old age. Wanda and other women raised affordable housing and financial insecurity as critical issues facing older women in Australia. Their concerns about the vulnerability of older women to housing precarity has been well documented (Nesbitt and Johnson, 2019; Darab et al., 2018). For $\mathrm{H}$ (aged 63) this was a personal experience and she was thankful to her friend who "has allowed me to build a room in a shed out the back. Without her, I would be one of the homeless women on the street". D, Wanda and H exemplify the remit of the 500 Strong and Flesh after Fifty projects; to generate political and critical debate through creative and artistic means.

Many of the women were, however, conscious of the fact that the 500 Strong project had largely attracted educated, middle-class women and that there were groups of women absent from the project. According to them, the precarity of housing and finances did not afford many older women the luxury to participate in such creative projects.

Triumph (aged 63) was a nurse and chose her pseudonym after the motorcycle that she rode to come for the interview. She decided to get involved in the photography session because she had always been interested in women's issues. For her, it was about contributing to images that depicted reality, stating, "I just don't like this Barbie doll, dolly bird look. We need to get out there and tell them women over 50 are interesting and vibrant". Because she was ineligible for the aged pension, Triumph had been forced to return to work after recovering from a stroke. She reflected on this, "the worst thing is we've all got to work till we are all nearly 70, especially in nursing, it's a really tough job". For her, being involved in the project was a way of boldly progressing the causes of older women through a public exhibition of their naked photographs.

The upcoming 500 Strong photography exhibition will represent bodies in their various shapes and sizes. A frequent criticism of ageing discourses is that there is a need to counter the essential narrative of abelism (the norm of the able bodied individual). For participants like Lisa and $\mathrm{E}$, this project celebrates the diversity of older women's bodies, thereby silencing the ableism trope through inclusion.

Both Lisa and Participant E were in their early 50s and they were worried about a future where older people with disabilities were not catered for in current policy and ageing discourses. Participant E, for example, voiced her concerns about the future, "I'm scared what's gonna happen to me when my parents pass away". For Lisa and Participant E, ageing has meant an amplification of the barriers they faced as women living with disabilities. Their contributions highlight the limitations of chronological ageing, particularly its neglect of disability and gender. At the same time, Lisa and Participant E did not want to be defined in deficit terms and saw themselves as contributing to society in a range of ways. Lisa's volunteering work at the eye and ear hospital and connections with community groups gave her a sense of wellbeing. Capturing the voices of Lisa and Participant E underscores the importance of how creativity, ageing and wellbeing responses are informed by the realities of life experiences.

For Lisa and Participant E, apart from their personal reasons for participating, the project offered a way to highlight their concerns about access to support services and their long-term 
needs. For them, the process of ageing amplified concerns they had always lived with: issues of isolation, stable housing, lack of social inclusion and ongoing support networks. Lisa wanted the needs of older women with disability to be heard, stating:

Listen to what people need, what their needs are and listen to the people who are ageing and disabled and, exactly what we need and what we don't need. It shouldn't be about money, it should be about services and people having the right to have what they need.

Older women with disability, older women in same-sex relationships, single older women and older women from diverse backgrounds are generally invisible in dominant ageing narratives and rarely depicted in the media (Calasanti, 1996; Marhánková, 2019). Some participants commented on dominant media images that featured fit and healthy heterosexual, able-bodied, white couples playing golf or going on luxury cruises. These images, they argued, did not reflect the realities of their lives and interests. Participating in the photography session was a way for them to initiate conversations about the range of ageing experiences and the need for multiple perspectives and diverse images of ageing.

\section{Discussion}

Why haven't we done this before? Why haven't we thought about the importance of this before? I do remember thinking this is important because it opens the door when thinking about what we're really like as women, especially as older women whose bodies have been the vehicle for a lot of dignity and various kinds of experience. In my case, the most astonishing of all, having babies. In the case of everybody, you know, sexual excitement, athletic prowess, kind of just ornating yourself when you want to. Here you are [in the photographs] without ornation, no ornamentation at all. (Participant Norn)

In this article we have argued that creativity as illustrated by older women's participation in a nude or semi-nude photography project offers critical perspectives on their ageing and wellbeing. Rather than viewing creativity as an intervention to enhance the wellbeing of older women, we have framed it as a dynamic and relational component in the lives of the women. This component has allowed us to engage with the individual and societal aspects of the participants wellbeing.

For the participants in this study, creativity has been conceptualized through the lenses of care, collaboration and critique. The intersections of creativity, wellbeing and ageing were realised in the celebration of individual achievements, highlighting financial and housing precarity, committing to intergenerational conversations, critiquing current policies that disadvantage older women and celebrating their bodies. Just as three older women artists, Louise Bourgeois, Rachel Rosenthal and Nettie Harris displayed their bodies "publicly, playfully, theatrically, flamboyantly, sardonically, ironically and pensively" in their artworks (Woodward, 2006, p. 167) so too did the participants of this study. Through their poses and props, the women contested the somewhat restricted and stereotypical images of older women while drawing on their biographical experiences to conceptualise ageing and wellbeing.

The themes of care, collaboration and critique we use in this study reflect the relational and discursive processes through which the participants understand and experience creativity, wellbeing and ageing. For Ana, Rose, Norn, Wanda and Wordsworth, notions of creativity were critical to who they were; their participation in the photography project was an extension of their 
creative capacities and central to their ageing and wellbeing. For others who described themselves as not being particularly creative, participation in the photography project, nonetheless, proved to be an exercise through which they could do something "outrageous", something they normally "wouldn't have chosen to do" (Abby).

Older women have been framed within popular culture as "invisible" or "hypervisible", either by their absence or their "aged" presence (Woodward, 2006, p. 163). This study illustrates the inherent contradictions the participants expressed when analysing their photography session. While some of the participants were critical of the invisibility that accompanies the ageing process for women, they also accepted the regimes of care that involved "looking young" such as coloring one's hair and keeping fit through regular gym visits. Pilcher and Martin (2020, p. 8) highlight this "in/visibility paradox" in their visual research study with participants aged between 52 and 85 years. Their participants felt they had to align with the norms of appearance for older women's bodies while at the same time recognizing the ageist implications for women. Similarly, we found that some of the participants in this study acknowledged the contradictions of posing for the photography session to contest ageist narratives while at the same time accepting that they wanted to conform to "acceptable" images of older women. Participant $\mathrm{H}$, for example, was critical of the portrayal of women in art and of advertisements that presented older women's bodies in "a sanitized way". She lauded the 500 Strong project for keeping older women's bodies in focus. Yet, she felt the need to color her hair, "to be seen again". This tension between images celebrating older women and maintaining a "youthful" look did not preclude Participant $\mathrm{H}$ from critiquing the ageist discourses that confront older women.

For a few of the women, ageing was an individual "moral agentive project" (Lamb, 2018, p. 274) and they wanted the photography session to reinforce their sense of individuality, independence and hard work. They had endured financial and personal hardship in their lives and felt they had emerged stronger through the adverse events. Their participation in the photography session was a testament to who they were and how they had addressed their wellbeing and ageing. Lamb would argue that the women's reflections illustrate their participation in the "biopolitics of ageing" (Lamb, 2018, 274) which emphasised fitness, health, independence and "successfully" managing the contours of one's life.

The inadequacies of simplistic binaries such as sick/healthy, strength/weakness associated with ageing and wellbeing discourses (Martin 2011; Sandberg 2013; Leahy 2020) were also illustrated through this study. Focusing on the dichotomies of active ageing versus impaired ageing (Leahy, 2019; 2020) does not, as this study argues, shed light on the potential for leading creative and fulfilling lives. As Ana pointed out, her creativity and wellbeing continues to flourish despite her health issues. While she may be restricted in the scope of her work, she continues to express her creativity and wellbeing through working on weaving projects with a group of refugee women in Melbourne. She has devoted herself to this project for the past few years. The capacity to live a stimulating life in one's later life is no less valid for the decline or impairment that accompanies the process of ageing. Ana's exploration of her body and its capacity through her creative pursuits including her photography session offers a subtle way of understanding the experiences of ageing and wellbeing. These alternative images provided by women like Ana help to shift discussion beyond "the two poles of active ageing and old age as decline" strands of thought (Enssle and Helbrecht, 2020, p. 8).

For other women like Participant D and Wanda, participation in the photography project was an opportunity to promote more nuanced understandings of ageing and wellbeing. By being part of a collective photography exhibition, they wished to highlight concerns of housing and financial insecurity that impact on women's experiences. Their creative preoccupations were less 
about promoting their healthy bodies and more about structural barriers faced by many older women. The participants in Lamb's (2018) ethnographic study illustrated similar differences in their ageing experiences. While some of her participants pursued healthy ageing through exercise and attention to diet, others were affected by anxieties of poor housing, unavailability of healthy food choices and inadequate access to medical care (Lamb, 2018). Definitions of the boundaries of old age varied among Lamb's participants: higher income participants constructed old age as an experience of their 70s and 80s whereas for lower income men and women old age was an experience that began at a much earlier age. Similarly, for the participants in this study, ageing and wellbeing notions were shaped by their experiences of living with disabilities, their social networks and community involvement and life and health experiences.

This study has also explored the creative responses of older women with disability and their wellbeing experiences. Dominant ageing discourses overlook the concerns and the contributions of women (and men) with disability. The literature exploring the intersections of disability and ageing is limited (Hebblethwaite et al., 2020) and models of participation that inform policies on ageing are based on "able-bodied and impairment free" assumptions (Raymond and Greiner, 2015, p. 198). Leahy (2018) outlines the paradox of ageing and disability; the two areas have been theorised separately "even though disabled people age, and most people who are ageing will experience disability" (p. 2). For Lisa and Participant E, wellbeing is an ongoing project and ageing processes are only a part of their overall life experiences. Their experiences of ageing intersected in familiar ways with experiences of living with disability. According to Participant E, "the invisibility was always there, I don't know what a 53-year old is supposed to act and feel" (sic).

Further opportunities for research generated by this study include an investigation of ageing and wellbeing using other creative media such as music, theatre or story telling; how creativity, ageing and wellbeing intersect in different socio-cultural and migration contexts and what the intersections of disability and ageing are. These questions will help to understand the complex and diverse lives of older people.

\section{Limitations}

A key limitation of this study is the absence of a diversity of women's voices; the study sample consisted predominantly of white, urban, middle-class and tertiary educated women. Indeed, much of the literature on successful ageing defaults to "a strong Anglophone bias" (Lamb, 2014, p. 42) as though there is a single guide for how people experience ageing. This does not account for the extreme heterogeneity of women over 50 who have a wide range of life experiences. Broader experiences of ageing and wellbeing will only be fully understood if the perspectives of Indigenous women, women with different types of disabilities, from LGBTQI communities, from working class backgrounds, from rural and regional Australia and from culturally and linguistically diverse backgrounds are incorporated. Their insights would make a richer contribution to building into the literature questions of abelism, class, place and race. The more perspectives that are included in research, the more useful this research will be in informing inclusive policy and practice that is relevant to the entire community. Even within the sample in this study it is noteworthy that ageing and wellbeing are conceptualised in a variety of ways by women from different age groups.

A further critical limitation of this study, which arose from the impact of the COVID-19 pandemic, is that a post-exhibition participatory workshop with the interviewees to discuss the project findings and participant reflections on the viewing of their images had to be deferred due to the postponement of the exhibition. This session would have contributed to a richer 
investigation of the notions of creativity, ageing and wellbeing through analysing women's images as a collective piece of work as well as individual portraits.

\section{Conclusion}

This paper has shown that qualitative interviews with a sample of women who participated in the 500 Strong photography project can enrich our understanding of the links between creativity, wellbeing and ageing. These links, we argued, are revealed through the themes of care, collaboration and critique that the creative project provided a unique venue to explore. Though the motivations for participating in the project and how it was experienced were diverse, nevertheless the analysis of the interviews showed consistent themes of raising the visibility of older women and their contributions while drawing attention to their concerns of structural insecurity. These insights alone show the potential for designing research around creative projects to understand older women's wellbeing and ageing experiences. These findings clearly support the need to give greater weight to qualitative research methods in less conventional research contexts to counterbalance existing singular approaches to the study of "ageing". The findings also contest binary assumptions such as: ability versus disability; independence versus dependence; illness versus wellness. Above all, the approach taken in this research showed that everyday experiences of ageing are complex and challenge categorization.

This study suggests ways of assimilating dimensions of creativity and wellbeing that would reframe and enrich discussions on ageing. Ageing, as the women who spoke about the 500 Strong project reinforce, is a rich concept that cannot be limited to abstract analysis that is often a feature of public health and policy disciplines. Ageing is by definition located in personal experience and sociopolitical and economic contexts. This is why women's experiences of illness or financial and housing precarity must be woven into their narrative of leading enriched lives.

The challenge for policy makers, therefore, is to move away from "productive" and "healthy" discourses of ageing as the hallmark for policy formulation. A considered, dynamic approach that addresses socio-economic contexts, life histories and structural factors that shape ageing processes will contribute to more robust ageing policy frameworks. This qualitative study of a sample of older women involved in the 500 Strong photographic project shows creative engagement as an important opportunity for practices of care, collaboration and critique. It suggests that a stronger focus on creative activities is a promising methodological approach which could contribute to a fuller understanding of how older women construct their sense of wellbeing.

\section{Acknowledgements}

We are grateful to all the women who made time to participate in this study and share their reflections. Our thanks also go to Professor Martha Hickey, Ponch Hawkes and Jane Scott. The study is supported by seed funding from the Creativity and Wellbeing Research Initiative (CAWRI) at the University of Melbourne. We also thank the two reviewers for their helpful suggestions.

\section{Conflict of interest statement}

The authors report no conflicts of interest.

\section{Authors}

Lila Moosad

University of Melbourne

lila.moosad@unimelb.edu.au 
Cathy Vaughan

University of Melbourne

\section{Publishing Timeline}

Received 2 September 2020

Accepted 26 November 2020

Published 17 December 2020

\section{References}

Adler, A. \& Seligman, M.E.P. (2016). Using wellbeing for public policy: Theory, measurement and recommendations. International Journal of Wellbeing, 6(1), 1-35. https://doi.org/10.5502/ijw.v6i1.429

Amabile, T.M. (2017). In pursuit of everyday creativity. The Journal of Creative Behavior, 51(4), 335-337. https://doi.org/10.1002/jocb.200

Archibald, M.M. \& Kitson, A.L. (2019). Using the arts for awareness, communication and knowledge translation in older adulthood: A scoping review. Arts \& Health, 12(2), 99-115. https://doi.org/10.1080/17533015.2019.1608567

Asquith, N. (2009). Positive ageing, neoliberalism and Australian sociology. Journal of Sociology, 45(3), 255-269. https://doi.org/10.1177/1440783309335650

Australian Association of Gerontology. (2018). Background Paper. Older women experiencing, or at risk of, homelessness. https://www.aag.asn.au/documents/item/2234

Baker, D. (2014). Creative approaches to working with older people in the public realm. Working with older people, 18(1), 10-17. https://doi.org/10.1108/WWOP-11-2013-0027

Bellass, S., Balmer, A., May, V., Keady, J., Buse, C., Capstick, A., Burke, L., Bartlett, R., \& Hodgson, J. (2019). Broadening the debate on creativity and dementia: A critical approach. Dementia, 18(7-8), 2799-2820. https://doi.org/10.1177/1471301218760906

Boyce-Tillman, J. (2019). When I grow down - music, spirituality and memory loss: A performative lecture on aging. Journal of Religion, Spirituality \& Aging, 31(2), 220-233. https://doi.org/10.1080/15528030.2018.1550734

Bryman, A. (2012). Social Research Methods (4th ed.). Oxford, Oxford University Press.

Calasanti, T.M. (1996). Incorporating diversity: meaning, levels of research, and implications for theory. The Gerontologist, 36, 147-156. https://doi.org/10.1093/geront/36.2.147

Calestani, M. (2013). An anthropological journey into well-being: Insights from Bolivia. Netherlands: Springer.

Cann, P. (2016). "Something to get out of bed for": Creative arts for a happily ageing population. Working with Older People, 20(4), 190-194. https://doi.org/10.1108/WWOP-09-2016-0025.

Cohen G.D. (2006). Research on creativity and aging: The positive impact of the arts on health and illness. Aging and the arts, Spring, 7-15.

Darab, S., Hartman, Y., \& Holdsworth, L. (2018). What women want: single older women and their housing preferences. Housing Studies, 33(4), 525-543. https://doi.org/10.1080/02673037.2017.1359501

Davidson, J.W., McNamara, B., Rosenwax, L., Lange, A., Jenkins, S., \& Lewin, G. (2014). Evaluating the potential of group singing to enhance the well-being of older people. Australasian Journal on Ageing, 33(2), 99-104. https://doi.org/10.1111/j.1741-6612.2012.00645

Dillaway, H.E., \& Byrnes, M. (2009). Reconsidering successful aging. A call for renewed and expanded academic critiques and conceptualizations. Journal of Applied Gerontology, 28(6), 702-722. https://doi.org/10.1177/0733464809333882

Dodge, R., Daly, A.P., Huyton, J., \& Sanders, L.D. (2012). The challenge of defining wellbeing. International Journal of Wellbeing, 2(3), 222-235. https://doi.org/10.5502/ijw.v2i3.4

Enssle, F., \& Helbrecht, I. (2020). Understanding diversity in later life through images of old age. Ageing E Society, 1-20. https://doi.org/10.1017/S0144686X20000379

Fischer, E. (2014). The good life: Aspiration, dignity, and the anthropology of wellbeing. Palo Alto: Stanford University Press. https://doi.org/10.1515/9780804792615 
Freixas, A., Luque, B., \& Reina, A. (2012). Critical feminist gerontology: In the back room of research. Journal of Women E Aging, 24(1), 44-68. https://doi.org/10.1080/08952841.2012.638891

Hebblethwaite, S., Young, L., \& Rubio, T.M. (2020). Pandemic precarity: Aging and social engagement. Leisure Sciences, 1-7. https://doi.org/10.1080/01490400.2020.1773998

Hodgson, V. (2018). Stereotypical representations of women and ageing: A review of the literature and photographic evidence. Postgraduate Journal of Women, Ageing and the Media, 4, 64-74.

Holstein, M.B., \& Minkler, M. (2007) Critical gerontology: reflections for the $21^{\text {st }}$ century. In Miriam Bernard and Thomas Scharf (eds) Critical Perspectives on ageing societies (Chapter Two). Bristol University Press: Policy Press. https://doi.org/10.1332/policypress/9781861348906.003.0002

Joseph, D., \& Southcott, J. (2013). Crafts and successful ageing: The Découpage Guild Australia. Craft Research, 4(2), 203-222. https://doi.org/10.1386/crre.4.2.203_1

Katz, S., \& Calasanti, T. (2015). Critical perspectives on successful aging: Does it "appeal more than it illuminates'? The Gerontologist, 55(1), 26-33. https://doi.org10.1093/geront/gnu027

Lamb, S. (2014). Permanent personhood or meaningful decline? Toward a critical anthropology of successful aging. Journal of Aging Studies, 29, 41-52. https://doi.org/10.1016/j.jaging.2013.12.006

Lamb, S. (2018). On being (not) old: Agency, self-care, and life-course aspirations in the United States. Medical Anthropology Quarterly, 33(2), 263-281. https://doi.org/10.1111/maq.12498

Leahy, A. (2018). Paradoxically thinking: Ageing with disability, disability with ageing. International Network for Critical Gerontology. https://criticalgerontology.com/category/current-events/

Leahy, A. (2019). Disability - an issue for all ages: Experiences of disability and ageing. Factsheet.

Leahy, A. (2020). Time to confront the portrait in the attic? Reflections on theories and discourses of ageing sparked by the COVID-19 crisis. British Society of Gerontology. Blogpost.

https://ageingissues.wordpress.com/2020/04/09/time-to-confront-the-portrait-in-the-attic-reflectionson-theories-and-discourses-of-ageing-sparked-by-covid-19/

Liddle, J.L.M., Parkinson, L., \& Sibbritt, D.W. (2013). Purpose and pleasure in late life: Conceptualising older women's participation in art and craft activities. Journal of Aging Studies 27, 330-338. https://doi.org/10.1016/j.jaging.2013.08.002

Marhánková, J.H. (2019). Places of (in)visibility. LGB aging and the (im)possibilities of coming out to others. Journal of Aging Studies, 48, 9-16. https://doi.org/10.1016/j.jaging.2018.11.002

Martin, W. (2011). Visualizing risk: Health, gender and the ageing body. Critical Social Policy, 32(1), 51-68. https://doi.org/10.1177/0261018311425980

Martin, A., Myers, N., \& Viseu, A. (2015). The politics of care in technoscience. Social Studies of Science, 45(5), 625-641. https://doi.org/10.1177/0306312715602073

Martin, W. \& Twigg, J. (2018). Ageing, body and society: Key themes, critical perspectives. Journal of Aging Studies, 45, 1-4. https://doi.org/10.1016/j.jaging.2018.01.011

Miller, E., Buys, L., \& Donoghue, G. (2019). Photovoice in aged care: What do residents value? Australasian Journal on Ageing, 1-5. https://doi.org/10.1111/ajag.12641

Nielsen, I.L. (2018). Aging with creativity. Journal of Gynecology and Women's Health, 11(5), 1-5. https://doi.org/10.19080/JGWH.2018.11.555823

Nesbitt, O., \& Johnson, L. (2019). "Homeless at home? Analysing the housing needs and insecurities of single, older, non-homeowning women." UQ UP Research Paper no. 2. https://uqurbanplanning.org/wp-content/uploads/2019/03/UQUP_Nesbitt_2.pdf.

Patterson, M.C., \& Perlstein, S. (2011). Good for the heart, good for the soul: The creative arts and brain health in later life. Journal of the American Society on Aging, 35(2), 27-36.

Pilcher, K., \& Martin, W. (2020). Forever "Becoming"? Negotiating gendered and ageing embodiment in everyday life. Sociological Research Online, 1-20. https://doi.org/10.1177/1360780420928380

Poulos, R.G., Marwood, S., Harkin, D., Opher, S., Clift, S., Cole, A.M.D., Rhee, J., Beilharz, K., \& Poulos, C.J. (2018). Arts on prescription for community-dwelling older people with a range of health and wellness needs. Health and Social Care in the Community, 27, 483-492. https://doi.org/10.1111/hsc.12669

Raymond, E., and Grenier, A. (2015). Social participation at the intersection of old age and lifelong disability: Illustrations from a Photo-Novel Project. Journal of Aging Studies 35, 190-200.

https://doi.org/10.1016/j.jaging.2015.08.001 
Richards, N., Warren, L., and Gott, M. (2012). The challenge of creating 'alternative' images of ageing: Lessons from a project with older women. Journal of Aging Studies, 26, 65-78. https://doi.org/10.1016/j.jaging.2011.08.001

Ryff, C.D., and Keyes, C.L.M. (1995). The structure of psychological well-being revisited. Journal of Personality and Social Psychology, 69, 719-727. https://doi.org/10.1037/0022-3514.69.4.719

Sabeti, S.(2015). Creative ageing? Selfhood, temporality and the older adult learner. International Journal of Lifelong Education, 34(2), 211-229. https://doi.org/10.1080/02601370.2014.987710

Sandberg, L. (2013). Affirmative old age - the ageing body and feminist theories on difference. International Journal of Ageing and Later Life, 8(1), 11-40. https://doi.org/10.3384/ijal.1652-8670.12197

Seligman, M.E.P. (2011). Flourish. New York, NY: Simon \& Schuster.

Tiiddenberg, K. (2018). Visibly ageing femininities: women's visual discourses of being over-40 and over50 on Instagram. Feminist Media Studies, 18(1), 61-76. https://doi.org/10.1080/14680777.2018.1409988

Tulle, E., and Krekula, C. (2013). Ageing embodiment and the search for social change. International Journal of Ageing and Later Life, 8(1), 7-10. https://doi.org/10.3384/ijal.1652-8670.13817

Twigg, J. (2013). Fashion and age: Dress, the body and later life. London: Bloomsbury. https://doi.org/10.2752/9781474290340

Twigg, J., and Martin, W. (2015). The challenge of cultural gerontology. The Gerontologist, 55(3), 353-359. https://doi.org/10.1093/geront/gnu061

Webster-Wright, A. (2019). Grace and grit: The politics, poetics and performance of ageing as a woman. Life Writing, 16(1), 97-111. https://doi.org/10.1080/14484528.2019.1521261

White, S.C. (2017). Relational wellbeing: Re-centering the politics of happiness, policy and the self. Policy E Politics, 45(2), 121-136. https://doi.org/10.1332/030557317X14866576265970

Woodward, K. (2006). Performing age, performing gender. NWSA Journal, 18(1), 162-189.

https://doi.org/10.2979/NWS.2006.18.1.162 